\title{
APPLICATION OF COMBINED-CYCLE PLANTS TO CONTROL THE ELECTRICAL LOAD CURVE
}

\author{
Olga Y. Romashova, Yegor A. Skrebatun a, Elvira Ya. Sokolova \\ National Research Tomsk Polytechnic University, 634050, Tomsk, Russia
}

\begin{abstract}
Conducted research based on the well-known information containing in publications that are listed in referees. Comparative calculation was made with using the method of incremental rate based on equal operation conditions. By virtue of conducted research was made a conclusion about prospective place of combined-cycle gas turbine in powertransmission system.
\end{abstract}

\section{Introduction}

At the present stage of power industry development the main tendency is the fuel consumption reduction for turbines with the simultaneous increase of their capacity as well as the decrease of harmful influence on the environment. Electric installations must have high maneuverable and flexible characteristics and high quality of released energy. Moreover, they must operate using the main types of fuel and have the ability to produce thermal energy. The above mentioned characteristics and advantages are typical for combined-cycle steam-gas plants (CCSGP) with different construction.

The high significance of CCSGP in the international and domestic power industry requires high attention to its role and place in the covering of electric load curves and demands. The factors that have influence on the control range of CCSGP are analyzed and studied in this article. Moreover, maneuverability, flexibility and the economic efficiency of CCSGP were compared with the efficiency of traditional steam power units (SPU).

\section{Factors limit the control range}

As it follows from the analysis of a large number of thermal schemes of CCSGP the most prospective scheme is the scheme of CCSGP with a heat-recovery boiler (HRB) (See figure 1). The number of circuits in this scheme makes up from one to three [1]. It is to be noted, that each of the main elements of this scheme has its own control range.

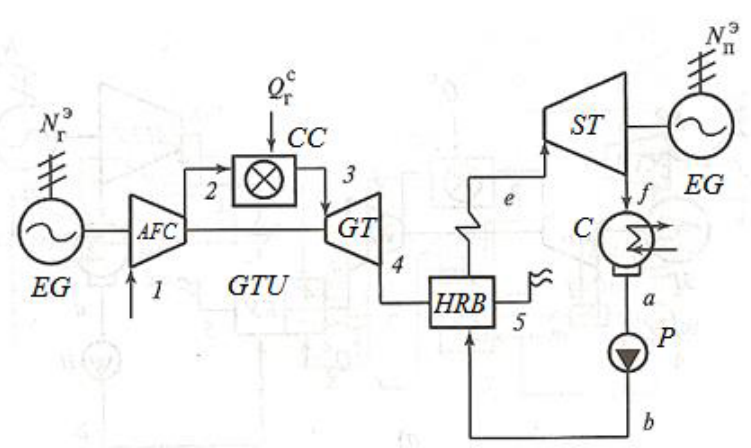

Figure 1. CCSGP with one circuit HRB: $A F C$ - axial-flow compressor; $C C$ - combustion chamber; $G T$ - gas turbine; $E G-$ electric generator; $G T U$ - gas-turbine unit; $H R B$ - heat recovery boiler; $S T$ - steam turbine; $C$ - condenser; $P$ - pump

Besides, the analysis was conducted in order to reveal the factors affecting the control range of the main equipment of CCSGP with HRB (steam turbine, gas-turbine unit, heat-recovery boiler).

Minimum safe output of a steam turbine is defined by such factors as:

- reliable operation of exhaust part of a turbine;

- operation of uncontrolled withdrawal of feedwater system.

\footnotetext{
${ }^{\text {a }}$ Corresponding author: eas8@tpu.ru
} 
Maximum safe output of a steam turbine is defined at the design stage and is limited by such factors as:

- throughput capacity of a turbine:

- thermal stress of details and turbine units.

Maneuverability and flexibility of gas-turbine unit (GTU) was studied on the basis of mutual influence of separate elements on the operation of the unit in the whole. The conducted analysis has shown that the next factors have influence on the control range of a unit:

$$
\begin{aligned}
& \text { - compressor surge limit; } \\
& \text { - outdoor (ambient) temperature; } \\
& \text { - gas-inlet temperature. }
\end{aligned}
$$

Outdoor temperature has the most influence on the operation of the main equipment of a CCSGP. Based on the results of the scheme calculation of CCSGP with HRB of 9FF type (General Electric) and steam turbine K-150-7,7 (PLC LMP) [1 ] the diagrammatic relation (See figure 2) was designed which characterizes the change of operating results depending on outdoor temperature. The ambient temperature rate is from $55{ }^{\circ} \mathrm{C}$ below zero to $35{ }^{\circ} \mathrm{C}$ above zero. The main fuel of the unit is natural gas.

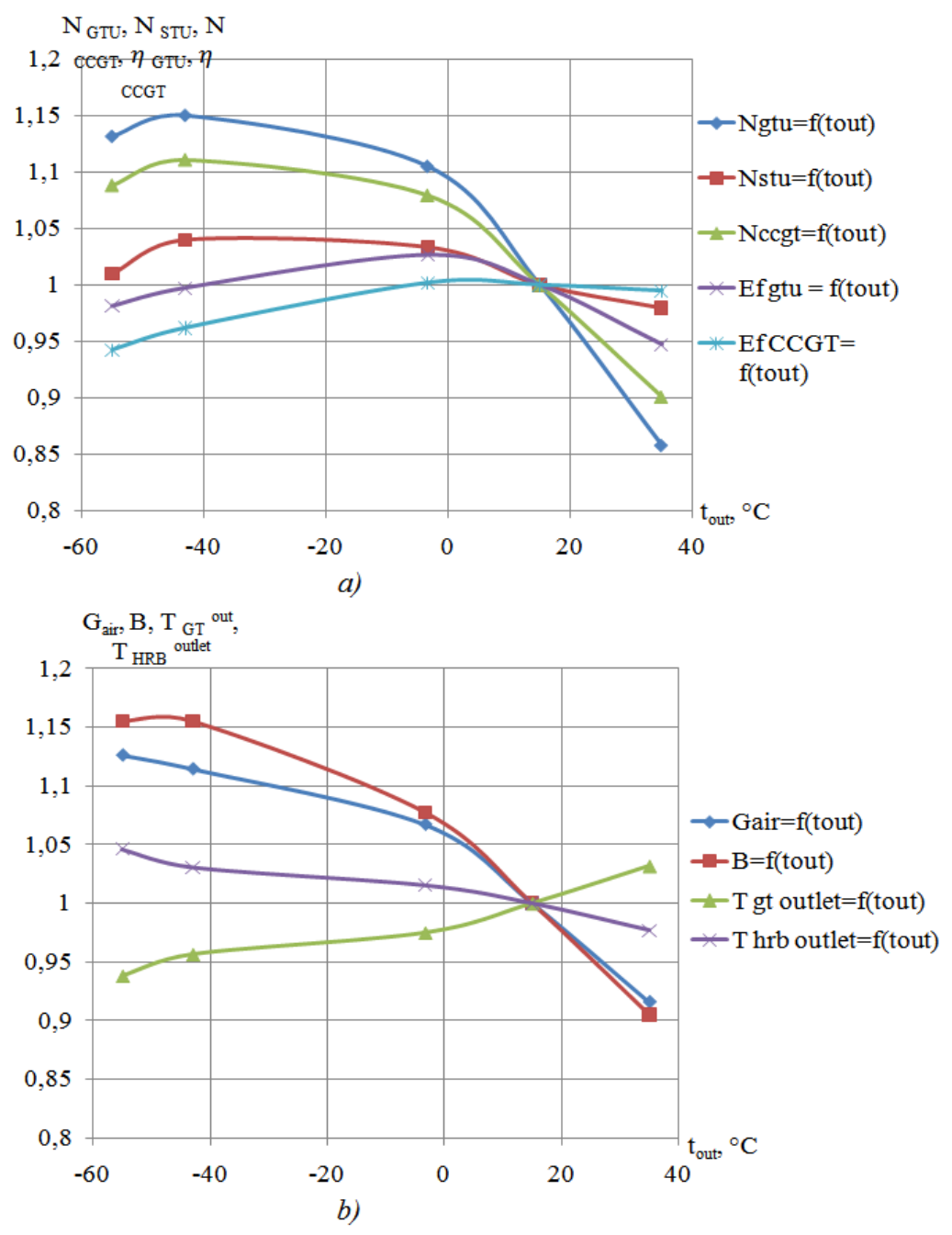

Figure 2. Characteristic curve of STU, GTU, CCSGP capacity and GTU and CCSGP efficiency (a), air-flow rate, fuel-flow rate, outlet temperature of gas turbine and heat recovery boiler (b) depending on outdoor temperature

As you can see in this picture with the decrease of the outdoor temperature there is the increase of CCSGP, GTU and STU capacity. However, when the outdoor temperature changes from 43 to $55{ }^{\circ} \mathrm{C}$ below zero the air flow rate changes slightly while the fuel consumption is constant. There is an insignificant water pressure reduction in a heat recovery boiler which leads to the decrease of heat transfer and to the increase of HRB outlet temperature. Thus, the capacity of units decreases. Since the air flow rate decreases it results in the increase of the gas turbine outlet temperature. When the outdoor temperature decreases from the calculating value $\left(15^{\circ} \mathrm{C}\right)$ the efficiency of GTU and CCSGP decreases too, because of the rise of heat losses. When the outdoor temperature increases from the calculating value $\left(15^{\circ} \mathrm{C}\right)$ we can also see that the efficiency decreases due to density of air reduction causing the decrease of air-flow rate and GTU capacity. The capacity of a steam turbine changes within $5 \%$.

The control range of a heat recovery boiler like an industrial boiler is defined by the next factors:

Minimum rate of capacity is defined by:

- hydraulic conditions of furnace tubes;

- operation conditions of superheaters;

- low-end temperature corrosion. 
Maximum rate of capacity is defined by:

- essential auxiliaries;

- destroying of back-end surface of boilers;

- bad separation in the drum.

Taking into account the results of the conducted analysis of the control range of the main equipment of CCSGP we can confirm that the basic engineering minimum of a steam turbine is equal to $15-20 \%$ of the rated capacity; a gas turbine unit can operate with zero capacity (autonomous operation); the low operation limit of a heat recovery boiler is $50 \%$ of the rated capacity. Therefore, a heat recovery boiler has minimum control range and defines the control range (minimum load) of the whole unit which is equal to $50 \%$ of the rated value.

\section{Start-up characteristic}

Besides the conducted research, the study of the control range, the comparison of the start-up characteristics of CCSGP and traditional STU with the same capacity (300 MW) (See figure 3) was made. To make this comparison the start-up diagram (from hot conditions) of a combined-cycle gas turbine and steam turbine was used. The start-up diagram of a heat recovery boiler was accepted for CCSGP as the less maneuverable part of it.

This diagram shows that CCSGP is able to achieve the nominal load considerably faster than a steam turbine. The time required to achieve the nominal load for CCSGP is three times less than for a steam turbine. It confirms that a combined-cycle gas turbine is able to operate under variable load.
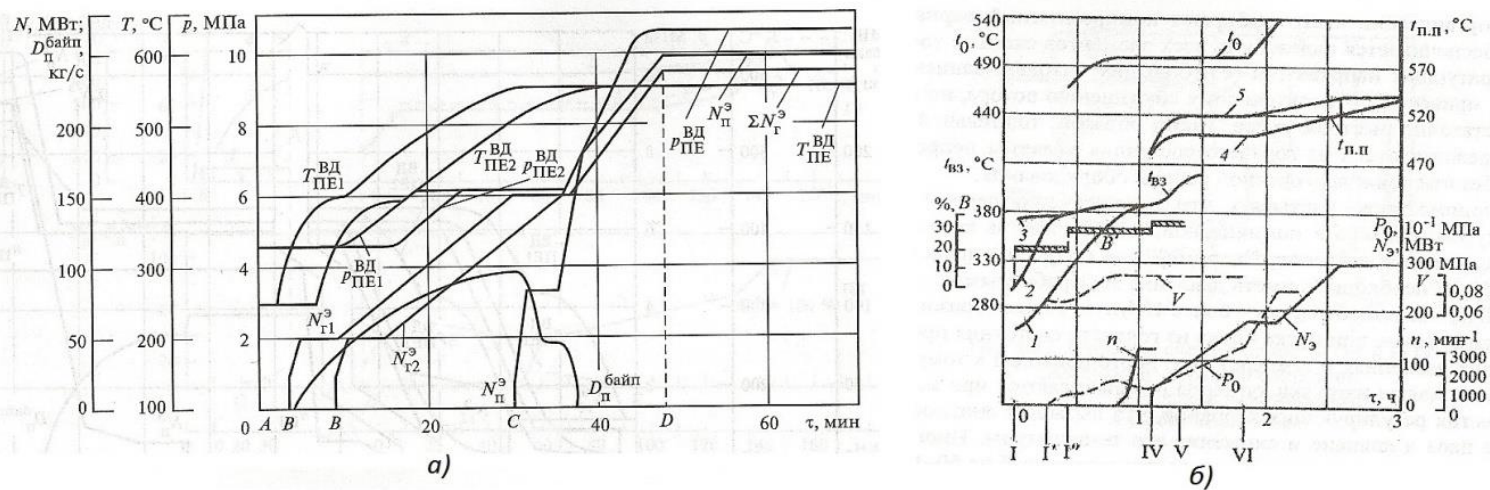

Figure 3. Start-up diagrams of CCSGP (a) and steam turbine unit (b) with capacity 300 MW (from hot conditions)

\section{Operating in power-transmission system}

Increasing share of CCSGPs in power-transmission system requires an analysis of combined operation with traditional STU. The interconnected and combined operation of such units as K-800-240, K-200-130, CCGT-400k and cogeneration CCSGP -80 was analyzed as an example.

Taking into account, that the method of incremental rate is mostly used for optimal power distribution of operating turbines the energy characteristics of units showing the relation between the consumption of equivalent fuel and electrical load were plotted. They determine the efficiency of the equipment operation under variable conditions. The well-known analytical characteristics were used for traditional steam turbines (K-800 and K-200) [2].Steam-consumption diagram was used for cogeneration CCSGP 80 unit (this unit operates under the condensing mode) (See figure 4)[1].

To calculate and asses CCSGP -400k the diagram of the increasing fuel-consumption rate for power generation with the decreasing the capacity of a unit (See figure 5) was used. The number of installation was chosen taking into account that nominal total load and is $800 \mathrm{MW}$ in all modes.

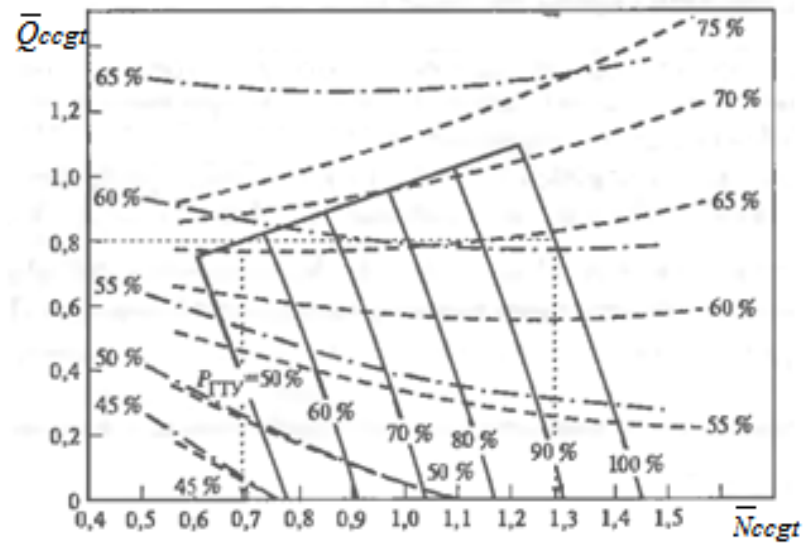

Figure 4. Steam-consumption diagram of cogeneration CCSGP -80 


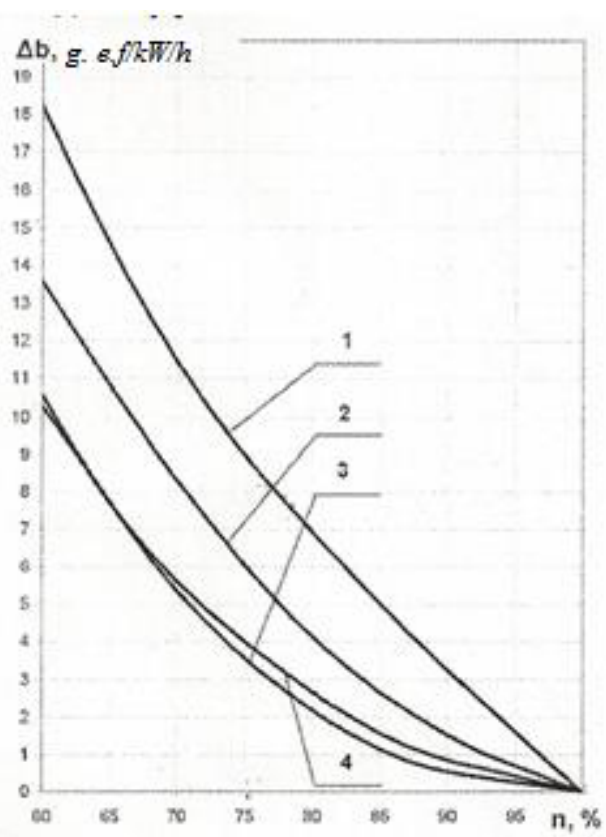

Figure 5 Increasing fuel-consumption rate for power generation with decreasing the capacity of a unit: 1 CCSGP -400кsec SGT54000F; 2 - CCSGP -285кcSGT5-3000E; 3 -STU-300-23,4; 4 - CCSGP -400 c GT26

Figure 6 presents the relation between the fuel consumption and load value. The angle of inclination of these characteristics shows the incremental rate of fuel.

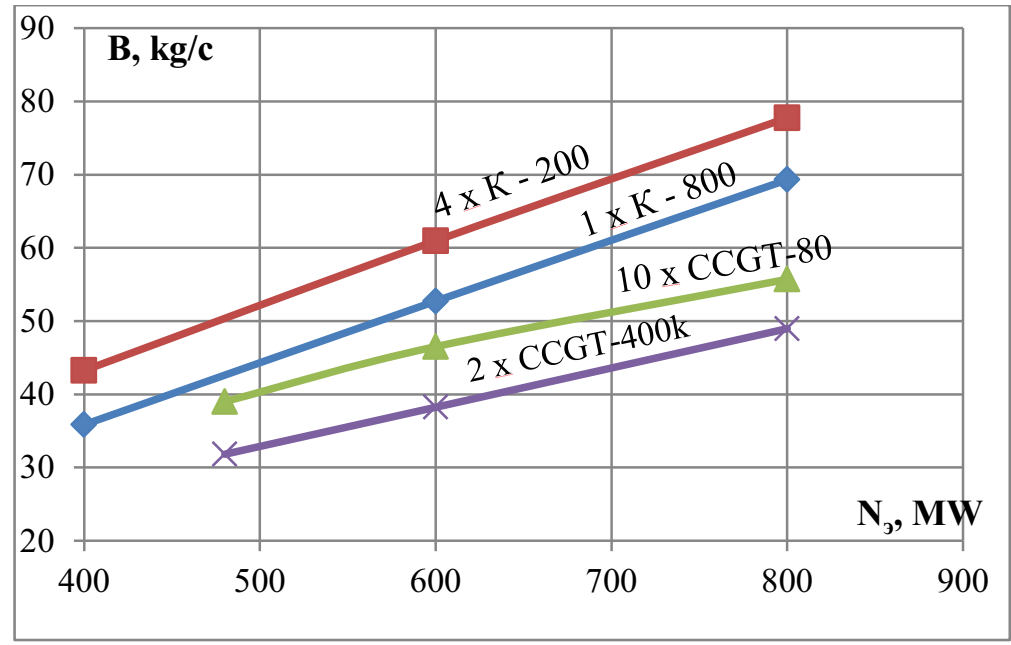

Figure 6. Fuel-flow characteristics of units

These relations confirm the following: with the increase of the capacity in the power transmission system there is an immediate load of CCSGP and unloading of condensing units with the power decrease.

\section{Conclusions}

Upon the conducted research, analysis and calculations the following conclusions were drawn:

- It is required more thorough research of the characteristics of the main equipment of CCSGP and their mutual influence on each other to analyze the maneuverability and flexibility of CCSGP;

- Load distribution between CCSGP and traditional steam units according to the method of incremental rate requires the immediate load increase of CCSGP;

- Combined-cycle gas turbines are flexible units. Due to their high economical characteristics and lower incremental rates they are able to operate in the variable part of the diagram.

- The selection of the flexible characteristics of CCSGP is defined by the specified operation zone and depends on the components of power system equipment.

Research was made in FSAE HE $<$ National research Tomsk Polytechnic university $>$ as a part of realization the federal target program $<$ Research and Development works in priority directions in the development of science and technology sector of Russia for 2014 - 2020 years $>$, unique identifier ACAED RFMEFI58114X0001 


\section{References}

1. Gas turbine and steam-gas installations of thermal powerstations:: teaching aid for institutes of higher education / S.V. Tsanev, V.D. Burov, A.N. Remezov; under editorship of S.V. Tsanev. - 2d Editionstereot. - M.: Publishing House MPEI, 2006. - 584 p.

2. The mode of operation and operation of thermal power stations: [Teaching aid for the major "Thermal power stations" / A.D. Katchan. - Mn.:Higher school, 1978. - 288 p.

3. The mode of operation and operation of thermal power stations: teaching aid / N.N. Galashov; Tomsk Polytechnic University. - Tomsk: Publishing House of Tomsk Polytechnic University, 2012. - 232 p.;

4. Thermal power stations: Student's book for institutions of higher education / V.Ya. Rizhkin; under editorship of V.Ya. Girshfeld. - 3d edition, revised and enlarged edition. - M.: Energoatomisdat, 1987. - 328 p.

5. Gas turbines. P. 1. Thermodynamic processes and heat exchange in units / Ya.I. Shney, V.M. Kapinos, I.V. Kotlyar. - Kiev: Publishing House «Higher Education», 1976. - 296 p.

6. Varying duty of gas turbine units /I.V. Kotlyar; under editorship of Ya.I. Shney. - M.: Mashgiz, 1961. - 231 p.

7. A.V. Moshkarin. The evaluation of operation indices of powerful steam-gas and steam-power plants under partial loads. / Yu. V. Melnikov, A. V. Moshkarin // Bulletin of Ivanovsk State Power Engineering University 2007.-2d edition - 234p.

8. The optimization of operate modes and parameters of thermal power plants: Student's book for the thermal power institutes of higher education / A.I. Andrushenko, R.Z. Aminov. - M.: Higher School, 1983. - 255 p. 